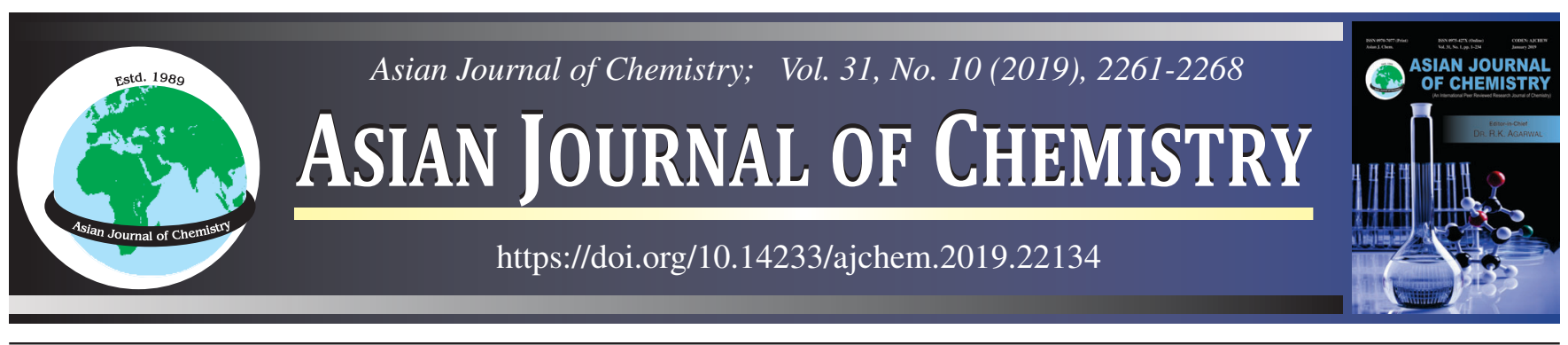

\title{
Thermal and Electrical Transport Properties of $o$-Substituted Polyanilines Encapsulated with CuO Nanoparticles
}

\author{
R. SUGANTHI ${ }^{\circledR}$ and S. JHANCY MARY*®®
}

Department of Chemistry, Auxilium College (Autonomous), Vellore-632006, India

*Corresponding author: Fax: +91 416 2247281; E-mail: jhancy2011@ gmail.com

Received: 14 April 2019;

Accepted: 20 May 2019;

Published online: 30 August 2019;

AJC-19533

Fabrication of substituted polyaniline nanocomposites with $\mathrm{CuO}$ results in hybrid materials with enhanced synergistic properties. Hence poly(2-chloroaniline)-composite-CuO, poly(2-chloroaniline)-composite-CuO/SDS, poly(2-methoxyaniline)-composite-CuO/SDS and poly(2-methylaniline)-composite-CuO/SDS nanocomposites were prepared chemically by in situ oxidative polymerization method. Characterization by a number of techniques such as FTIR, NMR and UV-visible spectroscopic methods, XRD and TEM are presented. The substituted polymers exhibited an appreciable interaction with the $\mathrm{CuO}(5 \mathrm{wt} \%)$ nano fillers. Integral Procedural Decomposition Temperature (IPDT) and Oxidative Index(OI) calculations were done to establish the stability to heat. Thermal stability of the materials follows the trend p2ClAni-CuO-SDS > p2ClAni-CuO> p2MeAni-CuO-SDS> p2OMeAni-CuO-SDS. The electrical conductivities of poly(2-chloroaniline)-composite-CuO and poly(2-chloroaniline)-composite-CuO/SDS measured are $1.46 \times 10^{-7}$ and $1.59 \times 10^{-7} \mathrm{~S} \mathrm{~cm}^{-1}$ respectively and the presence of anionic surfactant does not change the electrical conductivity behaviour. The poly(2-methoxyaniline)/

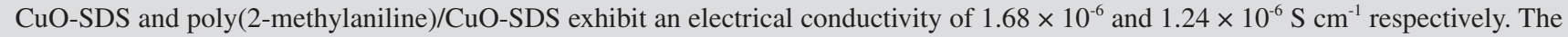
dielectric constant decreased with increase in frequency in the low frequency region due to electrical relaxation process. At low frequency there was a strong frequency dispersion of permittivity and above $2.5 \mathrm{~Hz}$ a frequency independent behavior was noted.

Keywords: $o$-Substituted polyanilines, $\mathrm{CuO}$ nanoparticles, Thermal, Electric transport.

\section{INTRODUCTION}

Conducting polymers have emerged as a significant group of polymeric materials in recent years due to their distinctive electrical, optical and thermal properties leading to a wide range of potential applications. Polyaniline (PANI) is a promising electrically conducting polymer used in batteries [1], sensors [2,3], electronic devices [4], super-capacitors [5] and corrosion protection in organic coating [6-8] due to its physical and chemical properties, good electrical conductivity (p-type), high environmental stability, low cost and facile fabrication [9-11]. PANI can also provide a good network for inorganic components and modify their properties and stability [12]. Polymer composites represent a new class of conventionally filled polymer material which increases strength, heat resistance and decreases flammability [13]. These materials are formed by dispersion of inorganic particles in an organic polymer matrix to spectacularly improve the performance properties of the polymers $[14,15]$. Composites of conducting polymers with suitable composition with inorganic material lead to desirable properties [16,17] and find numerous applications in electrical and electronic devices. These materials have emerged as suitable alternatives to overcome the limitations of micro-composites and monolithic polymers having polyconjugated structures and poor electrical conductivity.

Polyaniline and chloro-substituted polyaniline derivatives have engrossed considerable attention as reported in the preparation of their composites with metals and metal oxides, such as conducting polyaniline/WO [18], polyaniline/ZnO- $\mathrm{ZrO}_{2}$ [19], polyaniline/ $\mathrm{Fe}_{3} \mathrm{O}_{4}$ [20], polyaniline/ $\mathrm{TiO}_{2}$ [21], polyaniline $/ \mathrm{NiO}$ [22], polyaniline/ $\mathrm{Fe}_{2} \mathrm{O}_{3}$ [23], polyaniline/Se [24], polyaniline $/ \mathrm{Nb}_{2} \mathrm{O}_{5}$ [25], polyaniline/ $\mathrm{Co}_{3} \mathrm{O}_{4}$ [26] polyaniline/ZnO [27], polyaniline/CdS [28], polyaniline/Cu [29], polyaniline/ $\mathrm{CuO}$ [30], poly(2-chloroaniline)/ $\mathrm{SiO}_{2}$ [31], polyaniline-dodecylbenzenesulfonic acid (DBSA)/organophilic clay [5], polyaniline/ $\mathrm{SnO}_{2}$ [32] and poly(o-chloroaniline)/ZnO [33] and poly(2-

This is an open access journal, and articles are distributed under the terms of the Attribution 4.0 International (CC BY 4.0) License. This license lets others distribute, remix, tweak, and build upon your work, even commercially, as long as they credit the author for the original creation. You must give appropriate credit, provide a link to the license, and indicate if changes were made. 
chloroaniline)/CuO nano composites [34]. However, not much effort has been taken towards developing nanocomposites of substituted polyanilines resulting in enhanced thermal stability and high ionic conductivity at room temperatures.

The present work reports on the chemical synthesis, characterization, thermal and electrical transport properties of $-\mathrm{Cl}$, $-\mathrm{OCH}_{3},-\mathrm{CH}_{3}$, substituted polyaniline-CuO nanocomposites. An attempt has been taken to understand and compare the influence of $\mathrm{CuO}$ on the dielectric properties, impedance and electrical conductivity of poly(2-chloroaniline)-composite- $\mathrm{CuO}$ (p2ClAni-CuO), poly(2-chloroaniline)-composite-CuO/SDS (p2ClAniCuO-SDS), poly(2-methoxyaniline)-composite-CuO/SDS (p2OMeAni-CuO-SDS) and poly(2-methylaniline)-composite$\mathrm{CuO} / \mathrm{SDS}$ (p2MeAni-CuO-SDS) nanocomposites. The frequency dependence of dielectric constant, dielectric loss, imaginery modulus, real modulus and $\tan \delta$ are discussed. Complex impedance spectroscopic study was made for understanding the charge transport mechanism [35,36]. The frequency dependent conductivity and dielectric permittivity provide information on the electronic transport mechanism. It gives an insight into the presence of disorder in the molecular structure of the materials and the process of electrical transport along the polymer chains [35].

\section{EXPERIMENTAL}

The FT-IR measurements have been carried out using IRAffinity-1 Fourier Transform Infrared Spectrophotometer, Make -Shimadzu in the wave number range 4000 to $500 \mathrm{~cm}^{-1}$. The UV-visible analyses were carried out using Perkin ElmerLambda double beam spectrophotometer in the wavelength range $200-800 \mathrm{~nm}$. XRD analyses were performed on a Bruker AXS D8 advance using $\mathrm{Cu}$ as $\mathrm{X}$-ray source at the wavelength of $1.5406 \AA$ of angular range from $3^{\circ}$ to $135^{\circ}$. Thermo gravimetric analyses were carried out with a Perkin Elmer STA 6000 from room temperature to $700^{\circ} \mathrm{C}$ under inert gas atmosphere. Dielectric constants were measured by NOVO CONTROL technologies $\mathrm{GmbH}$ and Co. Electrical conductivity measurements were made using German model concept 80 in the frequency range from $10 \mathrm{~Hz}$ to $1 \mathrm{MHz}$ at room temperature. $\mathrm{Z}^{\prime \prime}$ vs. $\mathrm{Z}^{\prime}$ complex impedance plots were plotted for the nanocomposites and the bulk resistance $\left(R_{b}\right)$ was evaluated by analyzing the impedance data using ZSimpDemo software.

Preparation of polymer nanocomposites: The $\mathrm{CuO}$ nanocomposites of $-\mathrm{Cl},-\mathrm{OCH}_{3},-\mathrm{CH}_{3}$ substituted polyanilines have been chemically synthesized by in situ chemical oxidative technique by incorporating the nanoparticles obtained from Sigma Aldrich (particle size of $50 \mathrm{~nm}$ ) during the polymerization. The initiator used was ammonium persulphate and hydrochloric acid was used as dopant. Sodium lauryl sulphate (SDS) was used as a surfactant but it functionally acted as a dopant as well. The materials were obtained in the form of powder. The composites were obtained in the conducting emeraldine salt forms. After the polymerization was completed the polymer composites were repeatedly washed with deionized water and finally with few drops of acetone to remove the oligomers, dried and stored in air tight vials. Adopting the same procedure, poly(2-chloroaniline)/CuO was prepared in the absence of SDS. The polymer composite resulted in better yield in the presence of SDS. The composites were soluble in DMSO, DMF and partially soluble in toluene and chloroform. The percentage yield of the nano composites are given in Table-1.

\begin{tabular}{cc}
\multicolumn{2}{c}{ TABLE-1 } \\
YIELD OF THE NANOCOMPOSITES \\
\hline Polymer nanocomposites & Yield $(\%)$ \\
\hline (p2ClAni-CuO) & 37.00 \\
(p2ClAni-CuO-SDS) & 63.75 \\
(p2OMeAni-CuO-SDS) & 58.50 \\
(p2MeAni-CuO-SDS) & 73.50 \\
\hline
\end{tabular}

\section{RESULTS AND DISCUSSION}

FT-IR analysis: The infrared spectra of p2ClAni-CuO, p2ClAni-CuO-SDS, p2OMeAni-CuO-SDS and p2MeAni-CuOSDS nanocomposites are shown in Fig. 1. The incorporation of conducting polymer moieties into the respective polymer/nanostructure composites may be endorsed by FTIR spectral analysis $[37,38]$. The spectrum of p2ClAni-CuO shows a broad absorption peak around 3000 and $1209 \mathrm{~cm}^{-1}$ due to $-\mathrm{N}-\mathrm{H}$ and C-N stretching of the secondary amine respectively. The main peaks at 1577 and $1502 \mathrm{~cm}^{-1}$ correspond to quinone and benzene ring deformations, respectively. The additional peak at $580 \mathrm{~cm}^{-1}$ confirms the encapsulation of $\mathrm{CuO}$ nanoparticles on the polymer chains. The peak at $750 \mathrm{~cm}^{-1}$ is due to $\mathrm{C}-\mathrm{Cl}$ stretching frequency. In the IR of p2ClAni-CuO-SDS, absorption peaks at 3223 and $1290 \mathrm{~cm}^{-1}$ are due to $-\mathrm{N}-\mathrm{H}$ and $\mathrm{C}-\mathrm{N}$ stretching frequencies, respectively. The characteristic peaks due to $-\mathrm{C}=\mathrm{C}$ - stretching of quinonoid and benzenoid rings occur at 1573 and $1492 \mathrm{~cm}^{-1}$. The peaks at 2850 and $2922 \mathrm{~cm}^{-1}$ are due to the symmetric and asymmetric stretching frequencies respectively of - $\mathrm{CH}$ bonds in SDS. It also shows a peak at $574 \mathrm{~cm}^{-1}$ due to metal oxygen bond. The peak at $750 \mathrm{~cm}^{-1}$ is due to $\mathrm{C}-\mathrm{Cl}$ stretching frequency.

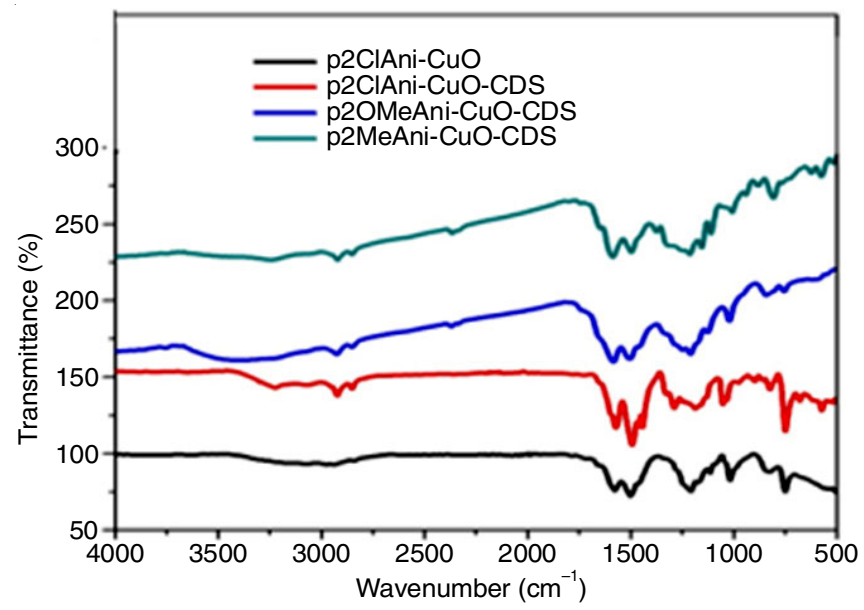

Fig. 1. IR spectra of p2ClAni-CuO, p2ClAni-CuO-SDS, p2OMeAni-CuOSDS and p2MeAni-CuO-SDS

The peaks at 900 and $825 \mathrm{~cm}^{-1}$ confirm the presence of 1,2,4-trisubstituted benzene rings. The presence of SDS as surfactant as well as dopant resulted in an increase in the yield of the polymer composite as shown in Table-1. The p2OMeAni$\mathrm{CuO}-\mathrm{SDS}$ shows a peak at $3400 \mathrm{~cm}^{-1}$ characteristic of $\mathrm{N}-\mathrm{H}$ stretching and the peak at $1282 \mathrm{~cm}^{-1}$ is assigned to aromatic C-N stretching vibration. The characteristic peaks due to quinonoid and benzenoid rings occur at 1585 and $1508 \mathrm{~cm}^{-1}$. The peak at 
$551 \mathrm{~cm}^{-1}$ is due to metal oxygen bond and the peak at $1211 \mathrm{~cm}^{-1}$ confirms the characteristic stretching of C-O-C present in methoxy groups attached to phenyl rings. The peaks at 2926 and 2852 $\mathrm{cm}^{-1}$ are due to the asymmetric and symmetric stretching frequencies of - $\mathrm{CH}$ bonds in SDS. The p2MeAni-CuO-SD shows peaks at $3244 \mathrm{~cm}^{-1}$ due to the presence of N-H stretching, 1587 and $1496 \mathrm{~cm}^{-1}$ due to the $-\mathrm{C}=\mathrm{C}$ - stretching of quinonoid and benzenoid rings, $1313 \mathrm{~cm}^{-1}$ due to aromatic $\mathrm{C}-\mathrm{N}$ stretching vibration, the peaks at 2922 and $2852 \mathrm{~cm}^{-1}$ due to the asymmetric and symmetric stretching frequencies of - $\mathrm{CH}$ bonds in SDS and the methyl substituents on phenyl rings and $576 \mathrm{~cm}^{-1}$ due to the presence of $\mathrm{CuO}$. The $\mathrm{C}-\mathrm{H}$ out of plane bending vibration of 1,2,4-trisubstituted benzene rings appear around 943 and $883 \mathrm{~cm}^{-1}$. The FTIR spectra indicate peaks of both substituted polyanilines $\left(-\mathrm{Cl},-\mathrm{OCH}_{3}\right.$ and $\left.-\mathrm{CH}_{3}\right)$ and the metal oxygen bond of $\mathrm{CuO}$ nanoparticles. The broad $-\mathrm{N}-\mathrm{H}$ stretching frequencies are certainly indicative of hydrogen bonds between hydrogen of amine nitrogens of the polymer chains and the oxygen present in $\mathrm{CuO}$ nanoparticles and the encapsulation of $\mathrm{CuO}$ nanoparticles was confirmed by FTIR spectra. The peak due to the vibrational mode of the protonated salt structure in the spectra around $1135 \mathrm{~cm}^{-1}$ indicates the formation of emeraldine salt structures.

UV-Visible analysis: The UV-visible spectra of p2ClAni$\mathrm{CuO}$, p2ClAni-CuO-SDS, p2OMeAni-CuO-SDS and p2MeAni$\mathrm{CuO}-\mathrm{SDS}$ measured in DMSO are given in Fig. 2 and the values are shown in Table-2.

The spectra show two major absorptions around 320-350 $\mathrm{nm}$ due to $\pi-\pi^{*}$ transition on the polymer chains and the absorptions around $550-600 \mathrm{~nm}$ are due to the $\mathrm{n}-\pi^{*}$ transition of quinonoid rings and corresponds to the localization of electrons [39].
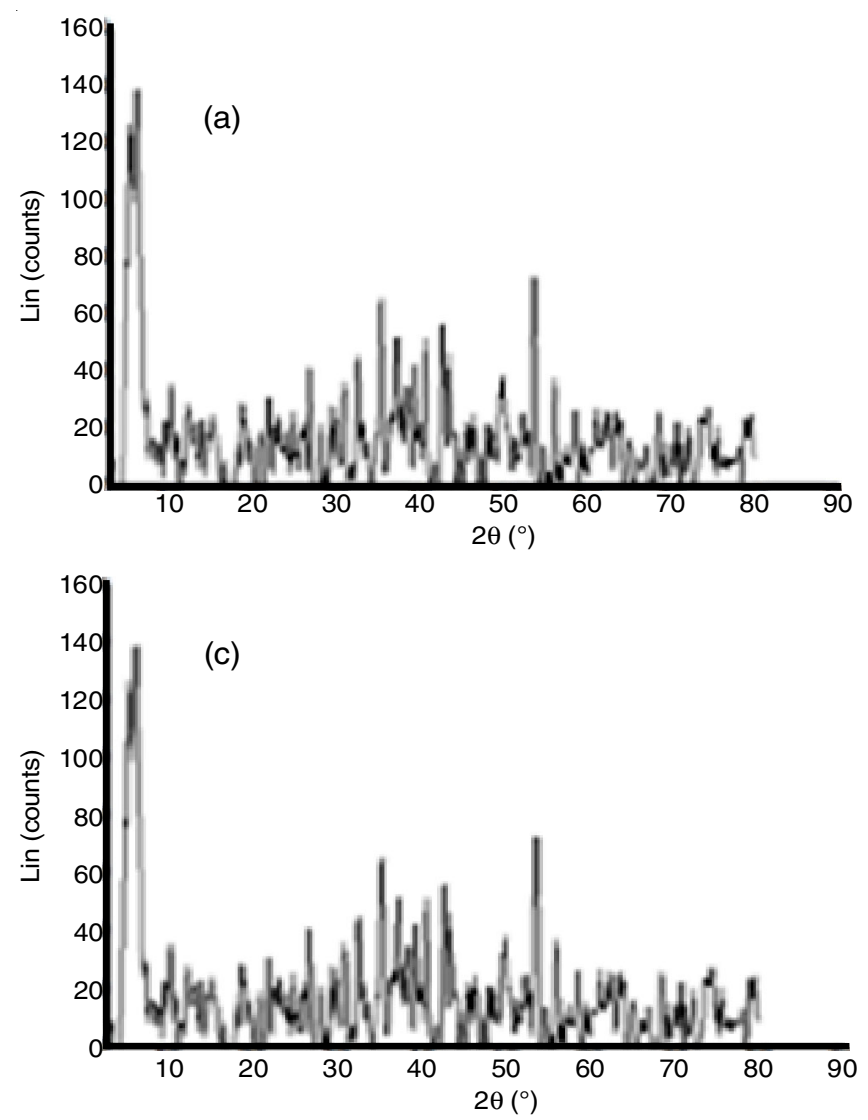

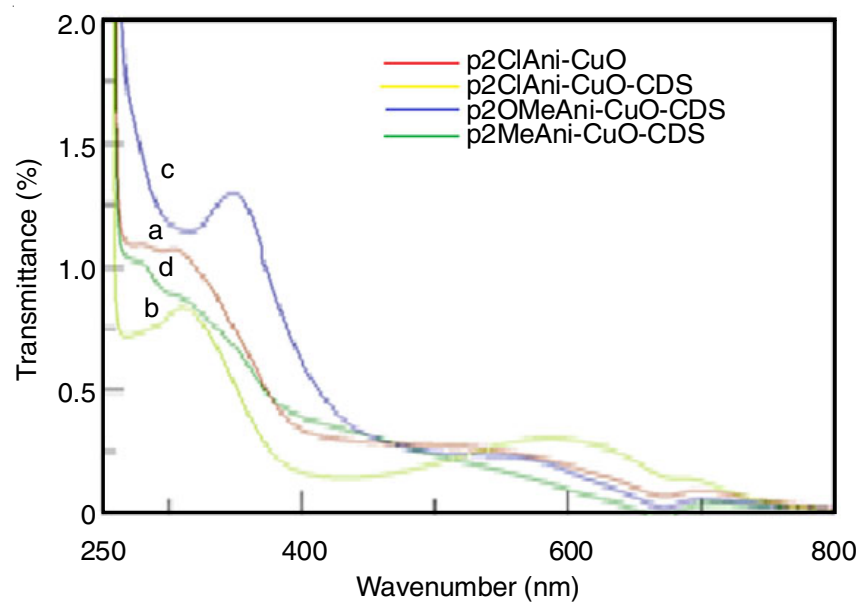

Fig. 2. UV-visible spectra of p2ClAni-CuO, p2ClAni-CuO-SDS, p2OMeAni$\mathrm{CuO}-\mathrm{SDS}$ and $\mathrm{p} 2 \mathrm{MeAni}-\mathrm{CuO}-\mathrm{SDS}$

\begin{tabular}{ccc} 
TABLE-2 & \\
\multicolumn{3}{c}{ ELECTRONIC ABSORPTIONS OF } \\
THE POLYMER NANOCOMPOSITES \\
\hline Polymer nanocomposites & $\pi-\pi^{*}(\mathrm{~nm})$ & $\mathrm{n}-\pi^{*}(\mathrm{~nm})$ \\
\hline p2ClAni-CuO & 320 & 550 \\
p2ClAni-CuO-SDS & 350 & 575 \\
p2OMeAni-CuO-SDS & 300 & 550 \\
p2MeAni-CuO-SDS & 320 & 600 \\
\hline
\end{tabular}

X-Ray diffraction: The XRD patterns of p2ClAni-CuO, p2ClAni-CuO-SDS, p2OMeAni-CuO-SDS and p2MeAni-CuOSDS nanocomposites are shown in Fig. 3a-d. The XRD patterns show the highly crystalline nature of the nanocomposites. The
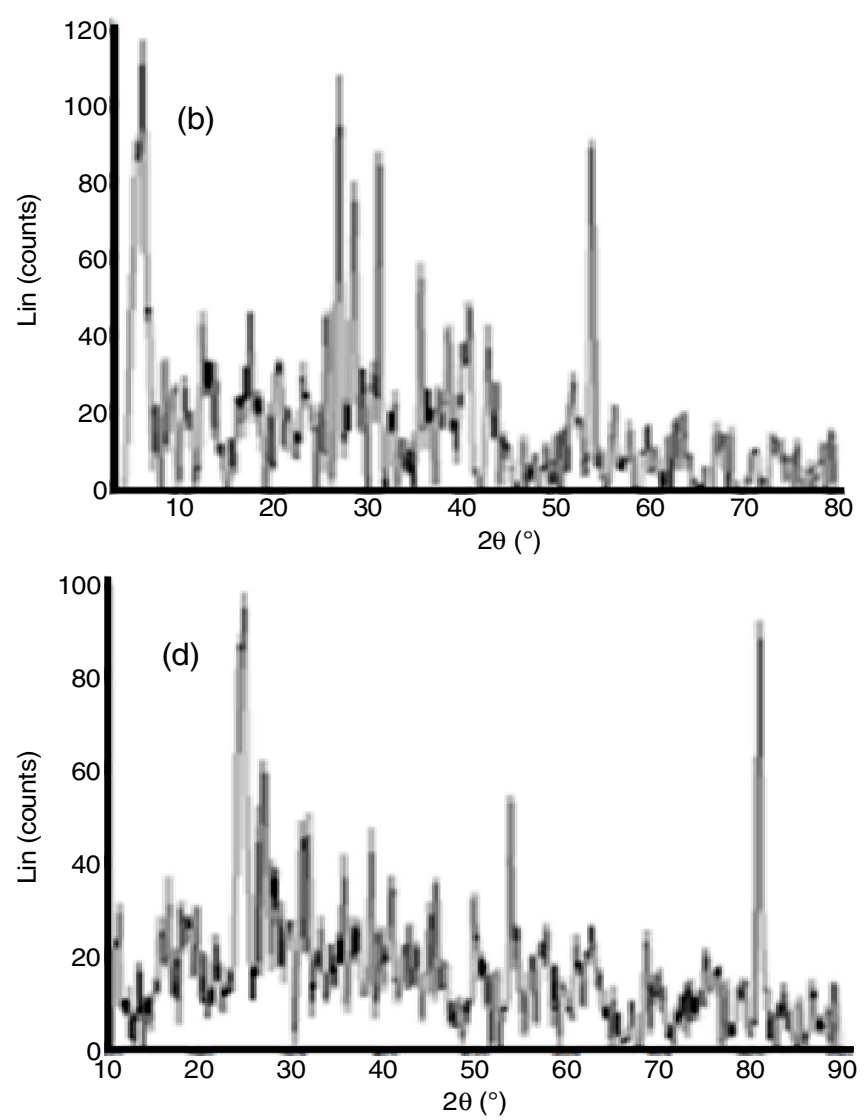

Fig. 3. XRD patterns of (a) p2ClAni-CuO (b) p2ClAni-CuO-SDS (c) p2OMeAni-CuO-SDS and (d) p2MeAni-CuO-SDS 
characteristic reflections of the polymer are observed at $2 \theta=$ $26^{\circ}$ and $35^{\circ}$ in p2ClAni-CuO and $2 \theta=31^{\circ}$ and $35^{\circ}$ in p $2 \mathrm{ClAni}-$ $\mathrm{CuO}-\mathrm{SDS}$. The other reflections coincide with the reflections of monoclinic structure of CuO; JCPDS card no. [89-5895]. The p2OMeAni-CuO-SDS nanocomposite show two sharp peaks between $2 \theta=29^{\circ}$ and $31^{\circ}$ due to the polymer and highly crystalline reflections of $\mathrm{CuO}$ nanoparticles. This observation from the XRD data endorses the uniform molecular level dispersion of $\mathrm{CuO}$ nanoparticles into the substituted polyaniline chains.

Thermal behaviour: The TGA/DTA analyses of p2ClAni$\mathrm{CuO}$, p2ClAni-CuO-SDS, p2OMeAni-CuO-SDS and p2MeAni$\mathrm{CuO}-\mathrm{SDS}$ nanocomposites are depicted in Fig. 4a-d. The thermogram of p2ClAni-CuO shows a broad endothermic degradation due to loss of water around $150^{\circ} \mathrm{C}$, exothermic decomposition at $320^{\circ} \mathrm{C}$ due to loss of dopant and decomposition of nanocomposite at $625^{\circ} \mathrm{C}$. The p2ClAni-CuO-SDS nanocomposite shows weight loss in four stages. The weight loss starts at 125 ${ }^{\circ} \mathrm{C}$ due to the endothermic loss of volatile impurities followed by loss of the dopants endothermically at 230.8 and $286.7^{\circ} \mathrm{C}$ due to removal of dodecyl sulphate anions and chloride ions and the decomposition of polymer back bone takes place at $683.64{ }^{\circ} \mathrm{C}$. The presence of sodium dodecyl sulphate anions as dopants increases the thermal stability of nanocomposite.

The p2OMeAni-CuO-SDS nanocomposite also undergoes a four step degradation process, weight loss at $68.80^{\circ} \mathrm{C}$ due to the endothermic loss of volatile impurities, the loss of dopant ion endothermically at $211.20^{\circ} \mathrm{C}$, loss of dodecyl sulphate anions
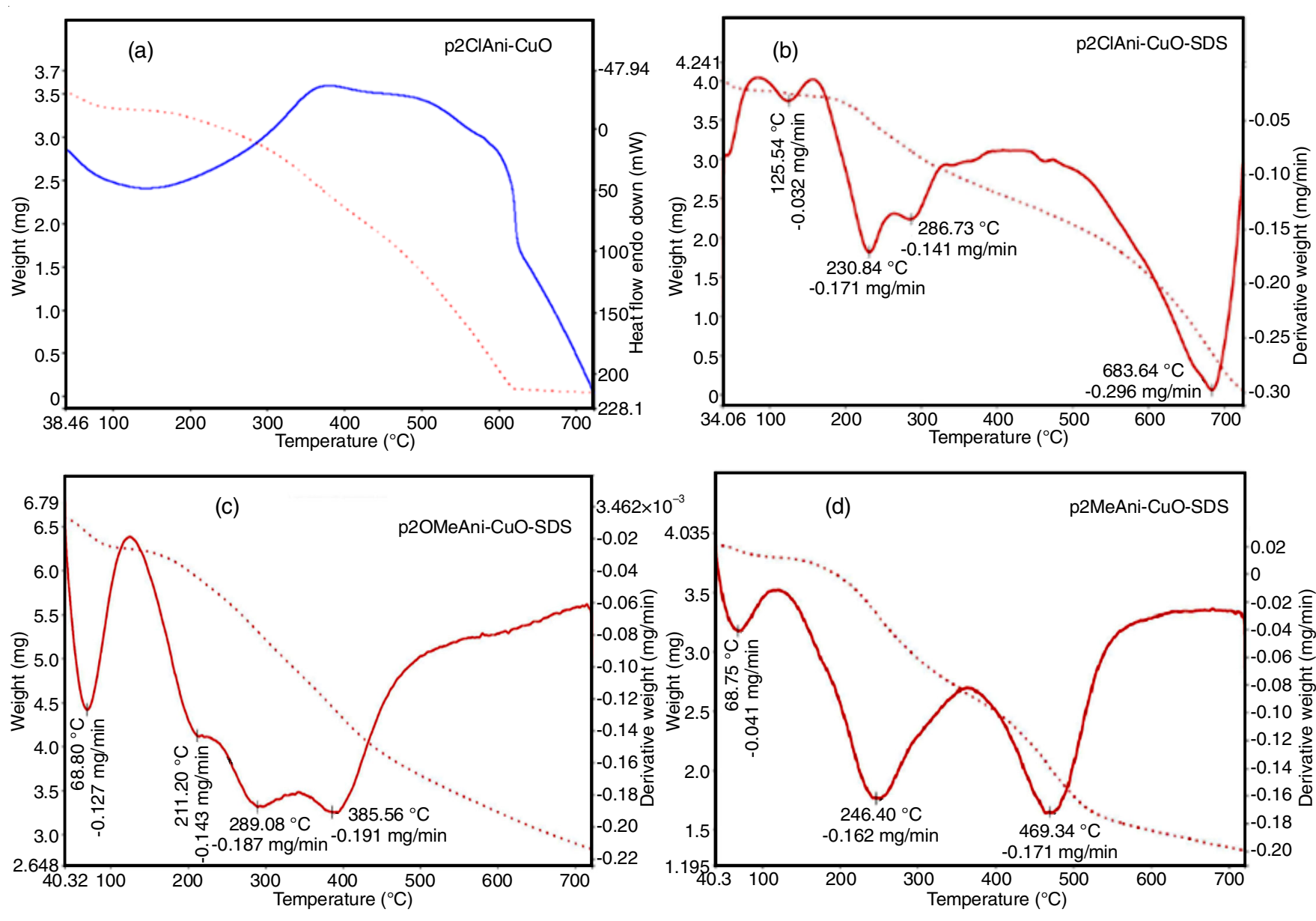

where $\mathrm{A}$ is the area ratio of total experimental curve defined by the thermogravimetric analysis, $\mathrm{K}$ is the coefficient, $\mathrm{T}_{\mathrm{i}}$ the initial experimental temperature, $\mathrm{T}_{\mathrm{f}}$ is the final experimental temperature in ${ }^{\circ} \mathrm{C}$. The oxidation index (OI) was calculated from the weight of carbon residue (CR), which is related to the flame retardant capacity of composites [40] and the values are shown in Table-3.

$$
\mathrm{OI} \times 100=17.5 \times 0.4 \mathrm{CR}
$$

\begin{tabular}{ccc}
\multicolumn{4}{c}{ TABLE-3 } \\
IPDT AND OI VALUES OF THE POLYMER NANOCOMPOSITES \\
\hline Polymer nanocomposites & IPDT & OI \\
\hline p2ClAni-CuO & 614 & - \\
p2ClAni-CuO-SDS & 881 & 0.238 \\
p2OMeAni-CuO-SDS & 424 & 0.416 \\
p2MeAni-CuO-SDS & 519 & 0.246 \\
\hline
\end{tabular}

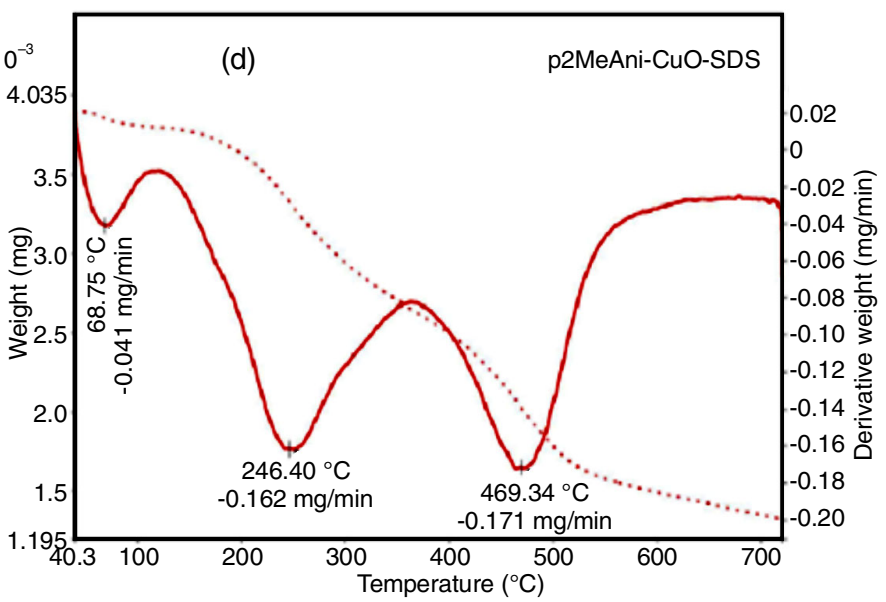

Fig. 4. TGA/DTA plots of a) p2ClAni-CuO b) p2ClAni-CuO-SDS c) p2OMeAni-CuO-SDS and d) p2MeAni-CuO-SDS 
The p2ClAni-CuO-SDS is thermally more stable than the p2ClAni-CuO and dodecyl benzene sulphonate anions give more rigidity to the polymer chains that resists the thermal degradation. The $-\mathrm{Cl}$ substituted polyaniline nanocomposite is the most stable nanocomposite probably due to the heat resistive property of chloro atoms. The - $\mathrm{CH}_{3}$ substituted polymer composite is more stable than $-\mathrm{OCH}_{3}$ substituted polyaniline nanocomposite which may be due to the bulkiness of ortho-substituted methoxy groups.

NMR analysis: The NMR spectra of p2OMeAni-CuOSDS and p2MeAni-CuO-SDS nano composites are depicted in Fig. 5a-b. The NMR spectra of p2OMeAni-CuO-SDS and p2MeAni-CuO-SDS nanocomposites confirm the presence of aromatic protons at $7.3 \mathrm{ppm}$. The peak corresponding to $3.6 \mathrm{ppm}$ is due to $\mathrm{N}-\mathrm{H}$ protons. The presence of protons of $\mathrm{O}-\mathrm{CH}_{3} / \mathrm{CH}_{3}$ groups is confirmed by the peak around $1.8 \mathrm{ppm}$.

(a)

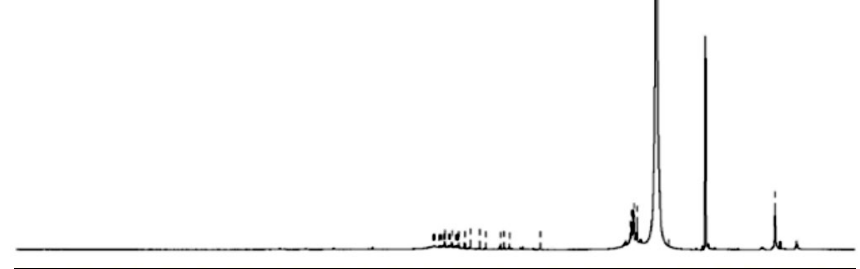

\begin{tabular}{lllllllllllllll}
\hline 14 & 13 & 12 & 11 & 10 & 9 & 8 & 7 & 6 & 5 & 4 & 3 & 2 & 1 & ppm
\end{tabular}

Fig. 5. NMR spectra of a) p2OMeAni-CuO-SDS and b) p2MeAni-CuO-SDS
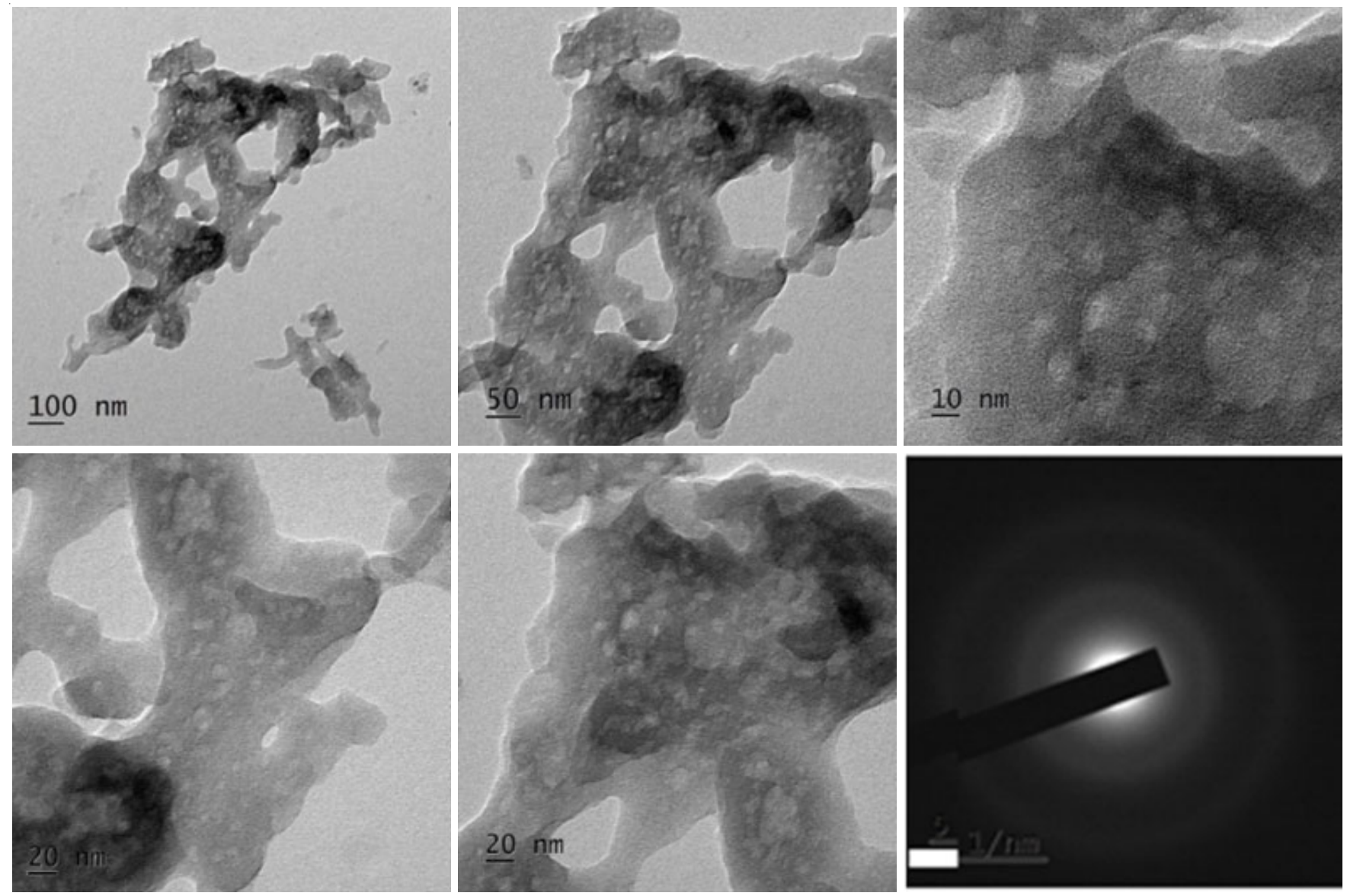

TEM: TEM images as shown in Fig. 6 of p2OMeAni$\mathrm{CuO}-\mathrm{SDS}$ nanocomposite confirms the successful intercalation of $\mathrm{CuO}$ nanoparticles into polymer chains. The $\mathrm{CuO}$ nanoparticles are uniformly dispersed in the polymer chains and the average particle size is of nanometer range.

Electrical conductivity: The complex impedance plots of solvent free pellets of p2ClAni-CuO,p2ClAni-CuO-SDS, p2OMeAni-CuO-SDS and p2MeAni-CuO-SDS measured at room temperature in the frequency region $50 \mathrm{~Hz}$ to $35 \mathrm{MHz}$ are shown in Fig. 7a-d, respectively.

The total electrical conductivity $(\sigma)$ values have been calculated using the formula, $\sigma=t / R_{b} A$ where $t$ is the thickness of the pellet, $\mathrm{A}$ is the area covered by silver electrodes in contact with the material and $R_{b}$ is the bulk resistance of the material. The ZSimpDemo software has been used to get the value of bulk resistance from the intercept on the real axis at the high

(b)

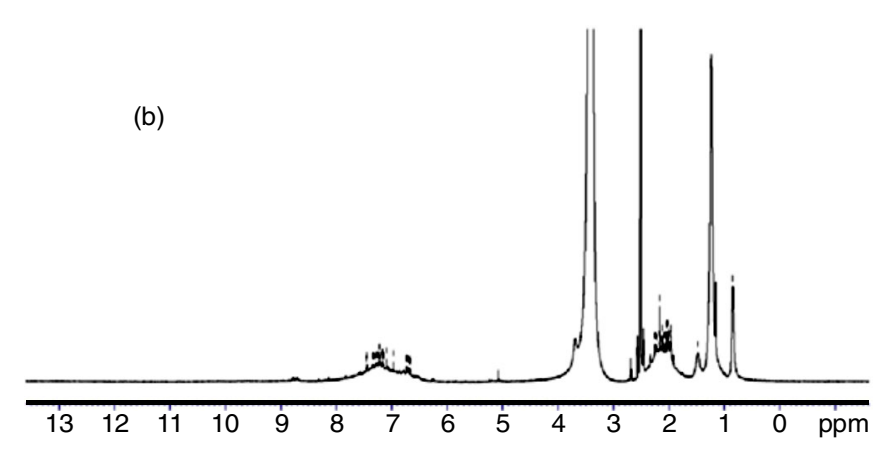
m 

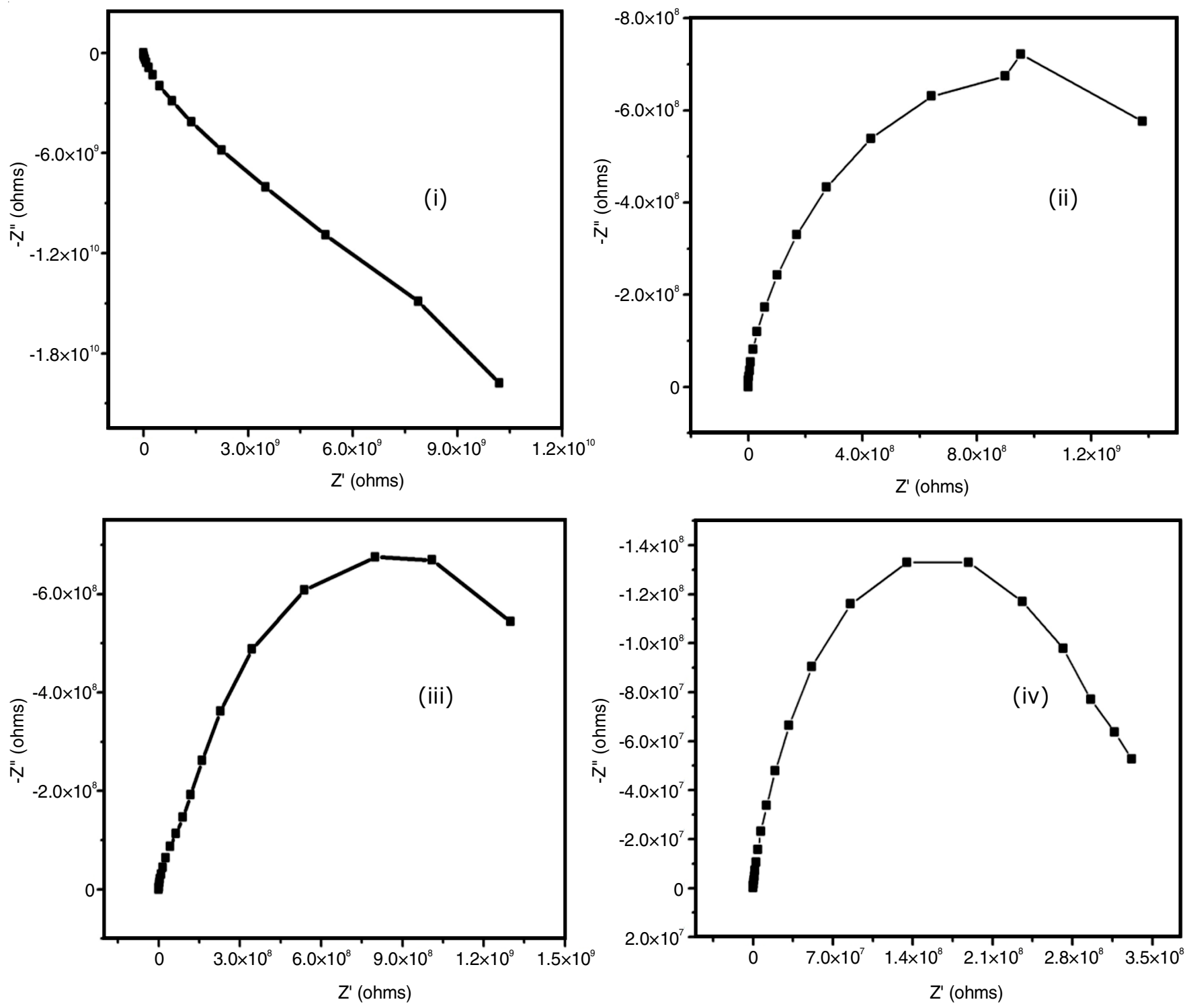

Fig. 7. Complex impedance plots of (i) p2ClAni-CuO (ii) p2ClAni-CuO-SDS (iii) p2OMeAni-CuO-SDS and (iv) p2MeAni-CuO-SDS

frequency portion of Nyquist plots. The electrical conductivity values are presented in Table-4.

\section{TABLE-4}

ELECTRICAL CONDUCTIVITY VALUES OF p2ClAni-CuO, p2ClAni-CuO-SDS, p2OMeAni-CuO-SDS AND p2MeAni-CuO-SDS

\begin{tabular}{cccc}
\hline $\begin{array}{c}\text { Polymer } \\
\text { nanocomposites }\end{array}$ & Thickness & $\mathrm{R}_{\mathrm{b}}$ & $\begin{array}{c}\text { Conductivity } \\
\left(\mathrm{S} \mathrm{cm}^{-1}\right)\end{array}$ \\
\hline p2ClAni-CuO & 0.86 & $7.49 \times 10^{6}$ & $1.46 \times 10^{-7}$ \\
p2ClAni-CuO-SDS & 0.94 & $7.51 \times 10^{6}$ & $1.59 \times 10^{-7}$ \\
p2OMeAni-CuO-SDS & 0.97 & $7.33 \times 10^{7}$ & $1.68 \times 10^{-6}$ \\
p2MeAni-CuO-SDS & 0.75 & $8.31 \times 10^{5}$ & $1.24 \times 10^{-6}$ \\
\hline
\end{tabular}

At high frequencies, these plots exhibit semi-circular arcs due to the bulk properties. The conductivity values are higher in the case of $-\mathrm{OCH}_{3}$ and $-\mathrm{CH}_{3}$ substituted polymer nanocomposites. The - $\mathrm{Cl}$ substituted polymer nanocomposite has conductivity reduced by an order of 10 which is due to the -I (inductive) effect of the substituent which reduces the electron density on the aromatic rings.
Fig. 8 shows the plot of dielectric constant versus frequency. The dielectric constant decreases with increase in frequency in the low frequency region due to electrical relaxation process. High dielectric permittivity at low frequency region is due to space charge polarization due to the presence of free charges at the interface [41]. At high frequencies, dielectric constant is independent of frequency as it remains almost constant. At low frequency there is a strong frequency dispersion of permittivity and above $2.5 \mathrm{~Hz}$ there is a frequency independent behaviour in permittivity.

Dielectric loss is a measure of energy dissipated and generally comprises of the contribution from ionic transport as well as polarization of a charge or dipole. The dielectric constant is high in - $\mathrm{Cl}$ and $-\mathrm{OCH}_{3}$ substituted polyaniline nanocomposites due to free charge motion within the material (Fig. 9), a phenomenon leading to conductivity relaxation [42]. Dielectric loss decreases with increases in frequency upto $2 \mathrm{~Hz}$. This is due to the free movement of the charges in the polymer matrix. On increasing the frequency upto $6 \mathrm{~Hz}$ there is no change in dielectric loss as it almost remains constant. 


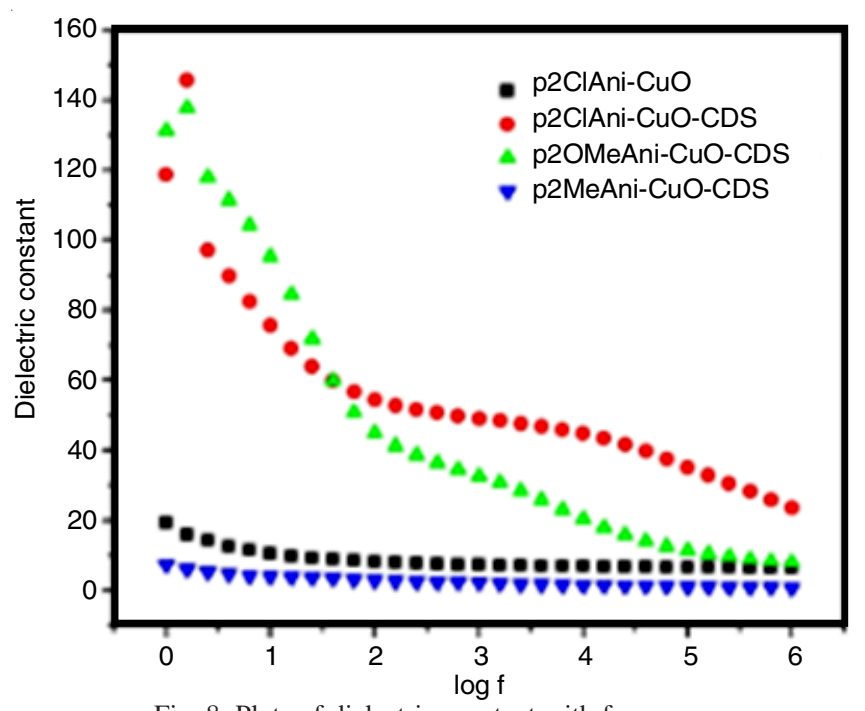

Fig. 8. Plots of dielectric constant with frequency

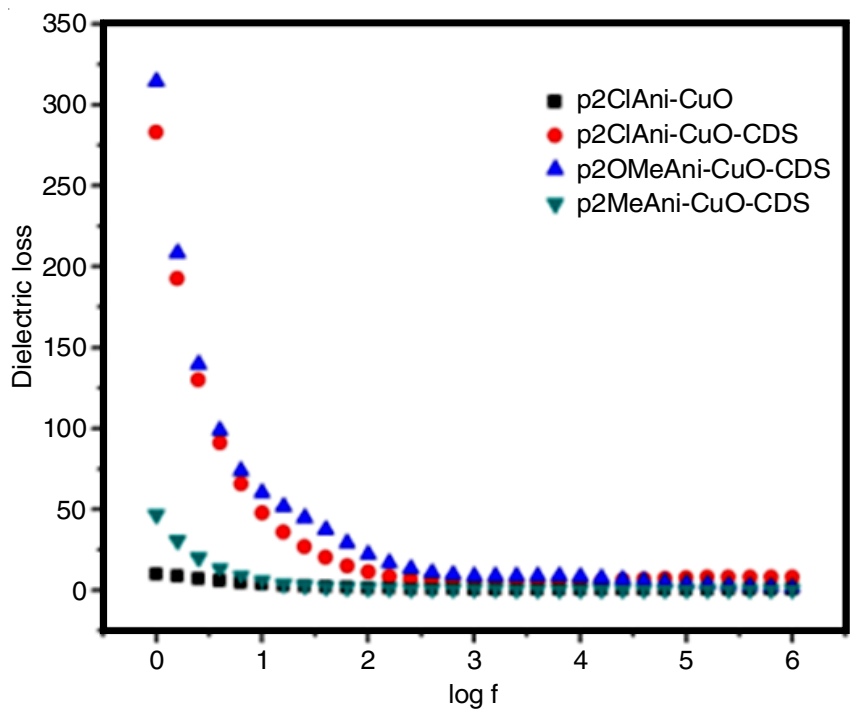

Fig. 9. Plots of dielectric loss with frequency

Fig. 10 shows the plot of $\tan \delta$ with frequency. Tan $\delta$ increases with increase in frequency upto $2.5 \mathrm{~Hz}$ due to the presence of relaxing dipolar. When frequency greater than $2.5 \mathrm{~Hz}$ is applied $\tan \delta$ does not vary much with frequency and this is attributed to non-relaxation dipole. The normalized modulus spectra in the form of real modulus $\left(\mathrm{M}^{\prime}\right)$ versus $\log \mathrm{f}$ and imaginery modulus $\left(\mathrm{M}^{\prime \prime}\right)$ versus $\log \mathrm{f}$ are given in Figs. 11 and 12, respectively. The flat portion from low frequency to high frequency in $-\mathrm{Cl}$ and $-\mathrm{OCH}_{3}$ substituted polyaniline $\mathrm{CuO}$ nano composites is due to large capacitance associated with the electrodes [43]. In the case of $-\mathrm{CH}_{3}$ substituted polyaniline- $\mathrm{CuO}$ nano composite, a rise in the curve is observed from low frequency to high frequency region which may be due to bulk relaxation effect [44].

\section{Conclusion}

The in situ chemical oxidative polymerizations were performed in the presence of the host material, $\mathrm{CuO}$ to synthesize p2ClAni-CuO, p2ClAni-CuO-SDS, p2OMeAni-CuO-SDS and p2MeAni-CuO-SDS nanocomposites. Spectroscopic results confirm the inclusion of $\mathrm{CuO}$ nanoparticles into $-\mathrm{Cl},-\mathrm{OCH}_{3}$ and $-\mathrm{CH}_{3}$ substituted polyaniline chains. The TGA results confirmed the thermal stability of nanocomposites. Thermal stability

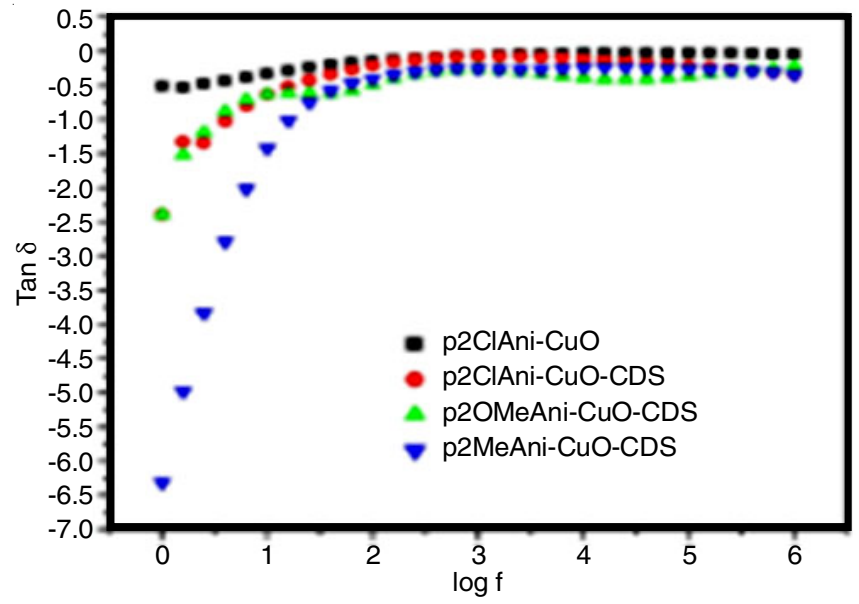

Fig. 10. Plots of $\tan \delta$ with frequency

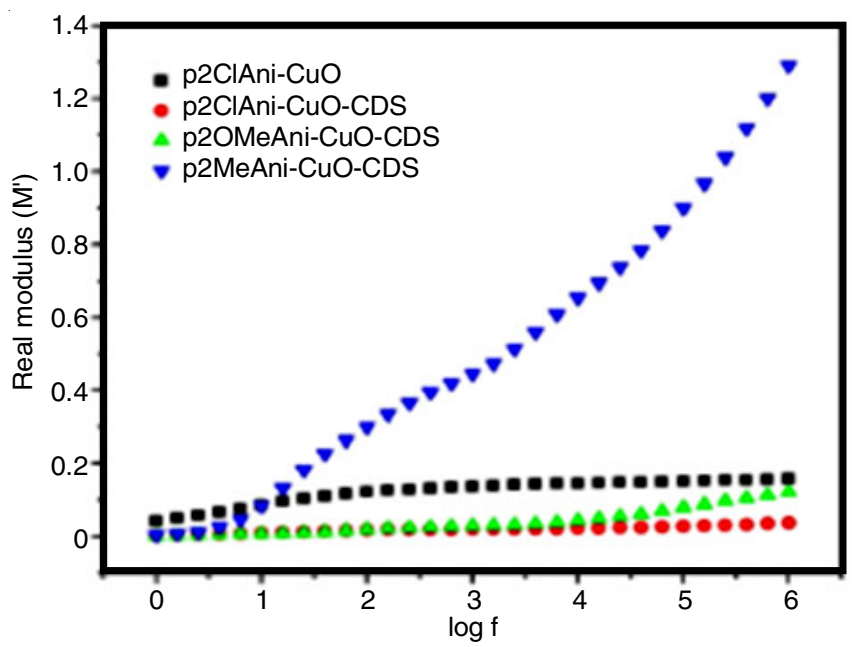

Fig. 11. Plots of real modulus with frequency

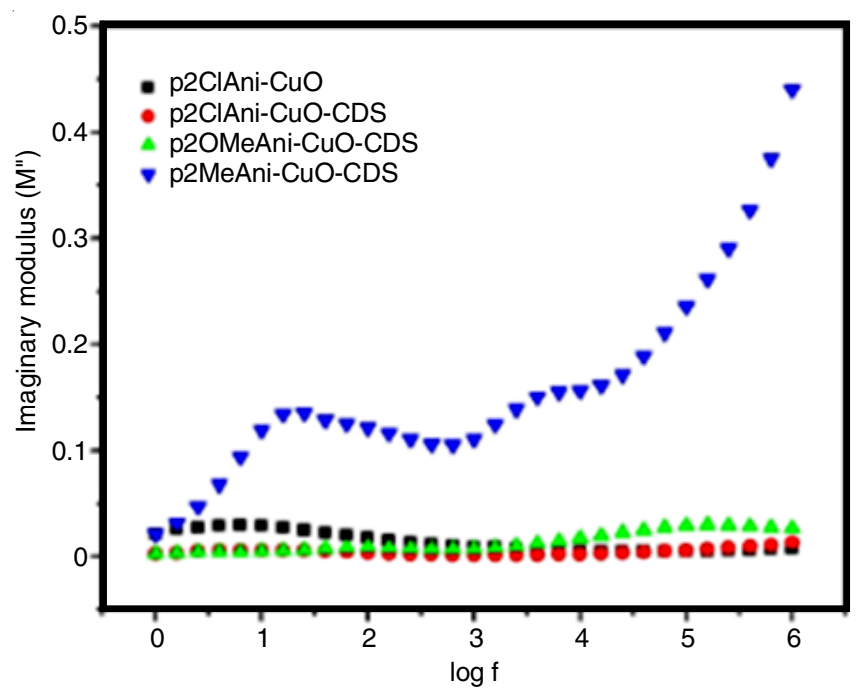

Fig. 12. Plots of imaginary modulus with frequency

of materials follows the order p2ClAni-CuO-SDS $>$ p2ClAni$\mathrm{CuO}>$ p2MeAni-CuO-SDS> p2OMeAni-CuO-SDS. Highly ordered XRD measurements suggests a metallic like conductive state. The conductivities as measured by the four probe technique is of the order of $10^{-7} \mathrm{~S} \mathrm{~cm}^{-1}$ in -Cl substituted nanocomposites and $10^{-6} \mathrm{~S} \mathrm{~cm}^{-1}$ in the case of $-\mathrm{OCH}_{3}$ and $-\mathrm{CH}_{3}$ substituted nanocomposites. Conductivity values are in the range of semi-cond- 
uctors. These materials have a significant role to play as energy storage devices.

\section{CONFLICT OF INTEREST}

The authors declare that there is no conflict of interests regarding the publication of this article.

\section{REFERENCES}

1. K. Gupta, P.C. Jana and A.K. Meikap, Synth. Met., 160, 1566 (2010); https://doi.org/10.1016/j.synthmet.2010.05.026.

2. K. Gurunathan, D.P. Amalnerkar and D.C. Trivedi, Synth. Mater. Lett., 57, 1642 (2003); https://doi.org/10.1016/S0167-577X(02)01045-5.

3. J. Deng, C.L. He, Y. Peng, J. Wang, X. Long, P. Li and A.S.C. Chan, Synth. Met., 139, 295 (2003); https://doi.org/10.1016/S0379-6779(03)00166-8.

4. N.G. Deshpande, Y.G. Gudage, R. Sharma, J.C. Vyas, J.B. Kim and Y.P. Lee, Sens. Actuators B Chemical, 138, 76 (2009); https://doi.org/10.1016/j.snb.2009.02.012.

5. W. Jia, E. Segal, D. Kornemandel, Y. Lamhot, M. Narkis and A. Siegmann, Synth. Met., 128, 115 (2002); https://doi.org/10.1016/S0379-6779(01)00672-5.

6. C. Peng, S. Zhang, D. Jewell and G.Z. Chen, Prog. Nat. Sci., 18, 777 (2008); https://doi.org/10.1016/j.pnsc.2008.03.002.

7. A. Olad, M. Barati and H. Shirmohammadi, Prog. Org. Coat., 72, 599 (2011); https://doi.org/10.1016/j.porgcoat.2011.06.022.

8. S. Sathiyanarayanan, V. Karpakam, K. Kamaraj, S. Muthukrishnan and G. Venkatachari, Surf. Coat. Technol., 204, 1426 (2010); https://doi.org/10.1016/j.surfcoat.2009.09.037.

9. B.H. Kim, J.H. Jung, S.H. Hong, J.W. Kim, H. Choi and J. Joo, J. Curr. Appl. Phys., 1, 112 (2001); https://doi.org/10.1016/S1567-1739(00)00021-3.

10. G.K. Prasad, T. Takei, Y. Yonesaki, N. Kumada and N. Kinomura, Mater. Lett., 60, 3727 (2006); https://doi.org/10.1016/j.matlet.2006.03.097.

11. B.K. Sharma, A.K. Gupta, N. Khare, S.K. Dhawan and H.C. Gupta, Synth. Met., 159, 391 (2009); https://doi.org/10.1016/j.synthmet.2008.10.010.

12. X. Li, X. Zhang, Z. Li and Y. Qian, Solid State Commun., 137, 581 (2006); https://doi.org/10.1016/j.ssc.2006.01.031.

13. A. Lagashetty and A. Venkataraman, Resonance-J. Sci. Educ., 10, 49 (2005).

14. N.N. Mallikarjuna, A. Venkataraman and T.M. Aminabhavi, J. Appl. Polym. Sci., 94, 2551 (2004); https://doi.org/10.1002/app.21144.

15. M.V. Murgendraapa and M.V.N. Ambika Prasad, Mater. Res. Bull., 41, 1364 (2006); https://doi.org/10.1016/j.materresbull.2005.12.011.

16. S.C. Raghavendra, S. Khasim, M. Revanasiddappa, M.V.N. Ambika Prasad and A.B. Kulkarni, Bull. Mater. Sci., 26, 733 (2003); https://doi.org/10.1007/BF02706771.

17. H.V. Vijayanand, L. Arunkumar, P.M. Gurubasawaraj, P.M.V. Sharma, S. Basavaraja, A. Saleem, A. Venkataraman, A. Ghanwat and N.N. Maldar, J. Appl. Polym. Sci., 103, 834 (2007); https://doi.org/10.1002/app.25186.

18. J. Zhu, S. Wei, L. Zhang, Y. Mao, J. Ryu, A.B. Karki, D.P. Young and Z. Guo, J. Mater. Chem., 21, 342 (2011); https://doi.org/10.1039/C0JM02090G.

19. S. Sultana, Rafiuddin, M.Z. Khan, K. Umar and M. Muneer, J. Mater. Sci. Technol., 29, 795 (2013); https://doi.org/10.1016/j.jmst.2013.06.001.

20. A.C.V. de Araújo, R.J. de Oliveira, S. Alves Júnior, A.R. Rodrigues, F.L.A. Machado, F.A.O. Cabral and W.M. de Azevedo, Synth. Met., 160, 685 (2010); https://doi.org/10.1016/j.synthmet.2010.01.002.
21. M.R. Nabid, M. Golbabaee, A.B. Moghaddam, R. Dinarvand and R. Sedghi, Int. J. Electrochem. Sci., 3, 1117 (2008).

22. B. I. Nandapure, S. B. Kondawar, M. Y. Salunkhe and A. I. Nandapure, Adv. Mater. Lett., 4, 134 (2013); https://doi.org/10.5185/amlett.2012.5348.

23. N.N. Mallikarjuna, S.K. Manohar, P.V. Kulkarni, A. Venkataraman and T.M. Aminabhavi, J. Appl. Polym. Sci., 97, 1868 (2005); https://doi.org/10.1002/app.21405.

24. E. Ozkazanc, S. Zor and H. Ozkazanc, J. Macromol. Sci. B: Phys., 51, $2122(2012)$ https://doi.org/10.1080/00222348.2012.664451.

25. Y.T. Ravikiran, M.T. Lagare, M. Sairam, N.N. Mallikarjuna, B. Sreedhar, S. Manohar, A.G. MacDiarmid and T.M. Aminabhavi, Synth. Met., 156, 1139 (2006); https://doi.org/10.1016/j.synthmet.2006.08.005.

26. M. D. Bedre, R. Deshpande, B. Salimath and V. Abbaraju, Am. J. Mater. Sci., 2, 39 (2012); https://doi.org/10.5923/i.materials.20120203.01.

27. F. Ahmed, S. Kumar, N. Arshi, M.S. Anwar, L. Su-Yeon, G.-S. Kil, D.-W. Park, B.H. Koo and C.G. Lee, Thin Solid Films, 519, 8375 (2011); https://doi.org/10.1016/j.tsf.2011.03.090.

28. P.K. Khanna, S.P. Lonkar, V.V.V.S. Subbarao and K.W. Jun, Mater. Chem. Phys., 87, 49 (2004); https://doi.org/10.1016/j.matchemphys.2004.04.003.

29. S. Sharma, C. Nirkhe, S. Pethkar and A.A. Athawale, Sens. Actuators $B$ Chemical, 85, 131 (2002); https://doi.org/10.1016/S0925-4005(02)00064-3.

30. D.M. Jundale, S.T. Navale, G.D. Khuspe, D.S. Dalavi, P.S. Patil and V.B. Patil, J. Mater. Sci. Mater. Electron., 24, 3526 (2013); https://doi.org/10.1007/s10854-013-1280-5.

31. A. Gök and S. Sen, J. Appl. Polym. Sci., 102, 935 (2006); https://doi.org/10.1002/app.24266.

32. Z. Hu, Y. Xie, Y. Wang, L. Mo, Y. Yang and Z. Zhang, Mater. Chem. Phys., 114, 990 (2009); https://doi.org/10.1016/j.matchemphys.2008.11.005.

33. A. Roy, R. Parveen, R. Deshpande, R. Bhat and A. Koppalkar, J. Nanopart. Res., 15, 1337 (2013); https://doi.org/10.1007/s11051-012-1337-z.

34. L.Porselvi, J. Sundararajan and S.J. Mary, J. Composites, 2014, Article ID 838975 (2014); http://dx.doi.org/10.1155/2014/838975.

35. R.P. McCall, E.M. Scherr, A.G. MacDiarmid and A. Epstein, Phys. Rev. B, 50, 5094 (1994); https://doi.org/10.1103/PhysRevB.50.5094.

36. A.G. MacDiarmid and A.J. Epstein, Macromol. Chem. Macromol. Symp., 51, 11 (1991); https://doi.org/10.1002/masy.19910510104.

37. M. Biswas, S. Sinha Ray and Y. Liu, Synth. Met., 105, 99 (1999); https://doi.org/10.1016/S0379-6779(99)00049-1.

38. C. Zhan, G. Yu, Y. Lu, L. Wang, E. Wujcik and S. Wei, J. Mater. Chem. C Mater. Opt. Electron. Devices, 5, 1569 (2017); https://doi.org/10.1039/C6TC04269D.

39. L.H.C. Mattoso, S.K. Manohar, A.G. MacDiarmid and A.J. Epstein, J. Polym. Sci. A Polym. Chem., 33, 1227 (1995); https://doi.org/10.1002/pola.1995.080330805.

40. H. Kumar, A.A. Kumar and Siddaramaiah, Polym. Degrad. Stab., 91, 1097 (2006); https://doi.org/10.1016/j.polymdegradstab.2005.07.003.

41. H.M. Kim, C.Y. Lee and J. Joo, J. Korean Phys. Soc., 36, 371 (2000).

42. J. Malathi, M. Kumaravadivel, G.M. Brahmanandhan, M. Hema, R. Baskaran and S. Selvasekarapandian, J. Non-Cryst. Solids, 356, 2277 (2010); https://doi.org/10.1016/j.jnoncrysol.2010.08.011.

43. I.M. Hodge, M.D. Ingram and A.R. West, J. Electroanal. Chem., 74, 125 (1976); https://doi.org/10.1016/S0022-0728(76)80229-X.

44. S.A. Suthanthiraraj and M.K. Vadivel, Ionics, 18, 385 (2012); https://doi.org/10.1007/s11581-011-0637-0. 